\title{
Research Paper: Effectiveness of Cognitive Emotion Regulation on Emotional Intelligence in Students With Hearing Impairment
}

\author{
Mohammad Ashori ${ }^{\text {1* }}$, Azam Rashidi ${ }^{1}$ (D)
}

1. Department of Psychology and Education of People with Special Needs, Faculty of Education and Psychology, University of Isfahan, Isfahan, Iran

\begin{tabular}{|c|c|}
\hline $\begin{array}{l}\text { Use vour device to san } \\
\text { and read the article online }\end{array}$ & Citation: Ashori M, Rashidi A. Effectiveness of Cognitive Emotion Regulation on Emotional Intelligence in Students With \\
\hline 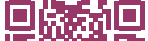 & Hearing Impairment. Iranian Rehabilitation Journal. 2020; 18(3):239-248. http://dx.doi.org/10.32598/irj.18.3.188.6 \\
\hline astris & dol'http://dx.doi.org/10.32598/irj.18.3.188.6 \\
\hline
\end{tabular}

Article info:

Received: 23 Oct 2019

Accepted: 16 Feb 2020

Available Online: 01 Sep 2020

\section{Keywords:}

Cognitive emotion regulation,

Emotional intelligence,

Hearing impairment

\section{ABSTRACT}

Objectives: Cognitive emotion regulation plays an important role in the emotional intelligence of students with hearing impairment. The present study was conducted to determine the effect of cognitive emotion regulation on emotional intelligence in students with hearing impairment

Methods: The present study was a quasi-experimental research with pre-test-post-test and control group design. This sample consisted of 30 students with a hearing impairment aged 16-20 years from the deaf school of Mir in Isfahan City, Iran in the 2018-2019 academic year. They were selected by convenient sampling method. The subjects were randomly divided into the intervention and control groups, and each group consisted of 15 students. The intervention group received a cognitive emotion regulation program in 8 sessions ( 45 minutes per session), while the control group did not participate in this intervention and was kept in the waiting list. Data gathering tools were an emotional intelligence test, administered before and after the training sessions. The obtained data were analyzed using a multivariate analysis of covariance and analysis of covariance in SPSS.

Results: The results indicated that cognitive emotion regulation had a positive and significant effect on emotional intelligence and its subscales of students with hearing impairment in the intervention group after the intervention $(\mathrm{P}<0.0001)$.

Discussion: Cognitive emotion regulation improved the emotional intelligence of students with hearing impairment. This program facilitates the improvement of the emotional intelligence in these students. Thus, paying attention to the cognitive emotion regulation program is essential for students with hearing impairment. 


\section{Highlights}

- The cognitive emotion regulation program has positive effects on emotional intelligence in students with hearing impairment.

- There were significant differences between the intervention (students with hearing impairment who received cognitive emotion regulation program) and control groups concerning the scores of emotional intelligence in students with hearing impairment.

- These changes in scores are due to the effects of the cognitive emotion regulation program in the intervention group.

\section{Plain Language Summary}

Students with hearing impairment are one of the groups of students with special needs. Problems in emotional intelligence are a common characteristic in students with hearing impairment. Emotional intelligence is very important for acquiring social skills and daily living skills. Students with hearing impairment have many problems in emotional intelligence that have a significant influence on the development of communication and social skills. It seems that the cognitive emotion regulation program improves many problems with these students. Cognitive emotion regulation is a psychosocial program for individuals with cognitive, attention, executive functions, and linguistic deficits. The present research was conducted on 26 students with a hearing impairment aged 16-20 years from the deaf school of Mir in Isfahan City, Iran to determine the effect of the cognitive emotion regulation program on them. The intervention group participated in 8 intervention sessions and was trained by the cognitive emotion regulation program, while the control group did not. The cognitive emotion regulation program improved emotional intelligence in students with hearing impairment.

\section{Introduction}

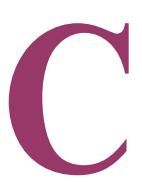

onnecting with the world around us by our senses is very important. We learn through what we see, hear, touch, smell, and taste, and when one of our senses is limited, our obtained information can be reduced [1]. According to the information processing model, we take information through our senses, especially hearing and sight. Therefore, the sense of hearing is one of the most important senses [2]. Hearing impairment occurs at about 1 per 750 live births. Deafness or hearing impairment places a child in a difficult situation somewhere between the world of the hearing and deaf [3]. Hearing impairment is a broad term that covers children with hearing loss ranging from mild to profound. Children with hearing impairment include children who are hard-of-hearing or deaf. The following are the commonly accepted definitions of deaf and hard-of-hearing based on an educationally oriented basis [4]. A deaf child is one whose hearing disorder prevents successful processing of linguistic information through hearing, with or without hearing aids. And, a child is hard of hearing, who has residual hearing sufficient to enable successful processing of linguistic information through hearing [5]. Hearing impairment can reduce social activities, create rejection feeling, withdrawal, and lower life quality. In general, hearing impairment affects all aspects of life [6] Therefore, hearing impairment is associated with emotional intelligence [7].

About 30 years ago, emotional intelligence was introduced by Salovey and Mayer. Emotional intelligence is a critical skill for success in daily living [8]. Emotional intelligence consists of four skills. To improve our abilities in the four emotional intelligence skills, we should understand better these skills. These four emotional intelligence skills are divided into two competencies: social competence and personal competence [9]. Personal competence included self-management and selfawareness skills. Social competence included relationship management and social awareness skills [10]. To be self-aware is to know ourselves as we are. Self-management is our ability to use awareness of our emotions to actively select what we say and do. Social awareness is key to managing our responses to changes, and an essential component of emotional intelligence [11]. Social awareness is the ability to take the perspectives of other people and apply it to our interactions with them. Relationship management refers to strategies for maintaining relations with others [9]. For years, it has been believed that students with hearing impairment cannot learn to speak, and the cognitive program cannot be appropriate for them [12]. Currently, the viewpoints of professionals 
and teachers have changed and it is recognized that students with hearing impairment can learn to speak better if taught with an appropriate method [4]. On the other hand, students with hearing impairment have problems in cognitive emotion regulation, that sometimes stated by teachers and parents [7].

The emotion management program is one of the programs which help people to regulate or adjust their emotions [13]. Emotion regulation plays an important role in situations such as depression and anxiety. Emotion regulation refers to an understanding of activities or processes that people can use them to evaluate, follow up, and influence the expression of the emotions [14]. Emotion regulation includes the external and internal processes that monitor, evaluate, and modify emotions [15]. Cognitive emotion regulation is the conscious and cognitive way of management of the intake of emotionally arousing information [16], and can be considered part of the wider concept of emotion regulation and is distinct from coping $[17,18]$. Cognitive change refers to re-evaluating one's situation or personal capacity to control one's situation so that it can influence one's emotions [19]. The cognitive emotion regulation strategies included otherblame, self-blame, catastrophizing, rumination, putting into perspective, positive reappraisal, positive refocusing, planning, and acceptance [20]. Strategies of cognitive emotion regulation that increase stress are called maladaptive ones, and strategies that can reduce it, are called adaptive strategies [21]. Using cognitive emotion regulation program helps people improve their positive emotions [20]. It seems that the cognitive emotion regulation program improves problems in children with hearing impairment [22].

Evidence demonstrates that the cognitive emotion regulation program has a considerable effect on emotional intelligence [4]. The research investigated the effectiveness of cognitive emotion regulation on the job satisfaction of employees. The results revealed that the strategies of cognitive emotion regulation improve the job satisfaction of subjects [23]. The results of the study showed who people with high emotional intelligence form their emotions. Also, people with good emotional intelligence successfully adjust their behaviors and emotions. Therefore, emotion regulation training improves emotional intelligence [24]. A study investigated how situational demands and individual differences influence the effectiveness of regulatory strategies. The results indicated that cognitive emotion regulation improved the emotional intelligence of subjects [25]. Another research assessed the effectiveness of emotion regulation on cognitive, social, and affective consequences. The findings indicated that the emotion regulation program improved cognitive and social consequences in the participants [26]. A study showed that emotional intelligence has closely related to emotion regulation and emotion management strategies training improved social sharing in people with hearing impairment [27]. The research finding indicated that emotion management strategies training reduced the emotion regulation difficulties and alexithymia in children with the oppositional defiant disorder [28]. The research results revealed that strategies of emotion regulation improved depression and anxiety in subjects [29]. Another research investigated the effect of emotional intelligence program on the mental health of students with hearing impairment. The results revealed that the emotional intelligence program improved the mental health of these students [7]. The research results revealed that the emotional intelligence training program improved self-esteem in students with hearing impairment [30].

According to some studies, children with hearing impairment have problems in emotional intelligence [7]. Moreover, the results of some studies show that emotional intelligence is very important in children with hearing impairment [30]. These children have problems in cognitive emotion regulation, which has negative effects on their emotional intelligence. Also, children with hearing impairment have many difficulties in communication skills in comparison with normal children. Considering this, the cognitive emotion regulation program is very beneficial for them [4]. When children with hearing impairment participate in a cognitive emotion regulation program, it could enhance their emotions [1]. Children with hearing impairment experience more cognitive emotion regulation problems than their normal peers and these problems adversely influence their emotional intelligence [5]. Regarding the studies conducted on the effectiveness of cognitive emotion regulation on emotional intelligence in students with hearing impairment, there have been few empirical investigations in this area. Furthermore, most studies conducted in this area are of a correlational type and a few studies have investigated the effectiveness of cognitive emotion regulation on emotional intelligence in students with hearing impairment. This issue indicates a research gap in this area as well as the importance and necessity of the present study. On the other hand, it seems that the education and rehabilitation of students with hearing impairment differ from their normal-hearing peers, and each group experiences different levels of cognitive development that can affect their emotional intelligence. Therefore, the purpose of this research was to determine the effect 
of cognitive emotion regulation on emotional intelligence in students with hearing impairment.

\section{Methods}

The present study was a quasi-experimental research with a pre-test, post-test and control group design. The statistical population included all students with hearing impairment who enrolled in high schools in Isfahan City in the 2018-2019 academic year. The total sample size was calculated as 30 students with a hearing impairment selected from Mir Deaf high school by a purposive sampling method. They were equally divided between the intervention and control groups. In other words, each group included 15 students.

The inclusion criteria were having hearing impairment in the range of 40 to $70 \mathrm{~dB}$, being diagnosed with prelingually and sensory-neural hearing impairment, having hearing aids in both ears, and aged 16-20 years. Also, the mother and child were both monolingual and Persian-speaking. This information was obtained from the subjects' academic files. The subjects would be excluded from the study if any symptom of significant health problems or neurodevelopmental disorder was seen in them. Also, having two absences from the intervention program sessions, participating in a similar intervention program at the same time, and not cooperating with the researcher were the exclusion criteria.
The Bradberry-Greaves emotional intelligence appraisal test was used for assessing the emotional intelligence of participants. This well-known test was developed by Bradberry and Greaves in 2003 [31]. The emotional intelligence appraisal test is a 6-point Likert-type scale scored from 1 (never) to 6 (always). This scale has 28 items in 4 subscales (self-awareness, self-management, social awareness, and relationship management). The total score of this test was obtained by summing scores of subscales and ranges from 28 to 168 [18]. Bradberry and Greaves reported the internal consistencies for the total scale as 0.42 . The Cronbach $\alpha$ coefficients were 0.85 to 0.91 for subscales. In Iran, Ganji, Mirhashemi, and Sabet reported the correlation coefficient for the total scale as 0.68 and the Cronbach coefficients as 0.73 , $0.87,0.78,0.76$, and 0.90 for the self-management, selfawareness, relationship management, social awareness, and total emotional intelligence, respectively [32]. In this study, the Cronbach coefficients were 0.81 to 0.89 for subscales.

Initially, the research implementation letter was obtained from Isfahan Exceptional Education Management. Then, the second researcher went to Mir Deaf School. The aims of the research were explained to the school manager. Following the inclusion and exclusion criteria, 26 students with hearing impairment were selected from students of this school by the purposive sampling method. Aims and importance of research were explained to mothers of the participants. They signed an

Table 1. The content of cognitive emotion regulation

\begin{tabular}{|c|c|c|}
\hline Session & Aims & Context of Sessions \\
\hline 1 & Awareness of emotions & $\begin{array}{l}\text { Introducing the program, its rationale and steps, the necessity for emotion regulation and } \\
\text { learning skills, the right perspectives about emotions, primary and secondary emotions, get- } \\
\text { ting help from emotions. }\end{array}$ \\
\hline 2 & $\begin{array}{l}\text { Emotional perception } \\
\text { skills and position choice }\end{array}$ & $\begin{array}{l}\text { Teaching and introducing emotions, identifying, naming, and labeling emotions, distinguish- } \\
\text { ing between different emotions, identifying emotions in physical and psychological states, } \\
\text { important factors in emotion regulation. }\end{array}$ \\
\hline 3 & Prevention skills & $\begin{array}{l}\text { Self-assessment with the goals of recognizing emotional experiences, levels of emotional } \\
\text { vulnerability, and self-regulation strategies, cognitive, physiological, and behavioral conse- } \\
\text { quences of emotional reactions, linking these outcomes with each other, introducing anger } \\
\text { and ways to overcome it. }\end{array}$ \\
\hline 4 & Position correction & $\begin{array}{l}\text { Preventing social isolation and avoidance, problem-solving strategy training, interpersonal } \\
\text { dialogue, assertion, and conflict resolution. }\end{array}$ \\
\hline 5 & Expanding attention & Stop rumination and worry, attention training and worry. \\
\hline 6 & Cognitive assessment & $\begin{array}{l}\text { The role of the mind in producing, maintaining, increasing, or decreasing emotional respons- } \\
\text { es, identifying false evaluations and their impact on different emotional states, re-evaluating } \\
\text { strategy training. }\end{array}$ \\
\hline 7 & Response adjustment & $\begin{array}{l}\text { Identifying the use of inhibition strategies and evaluating its emotional consequences, ex- } \\
\text { posure, emotion training, behavior modification through changing different reinforcement, } \\
\text { emotional discharge, relaxation, and reverse action. }\end{array}$ \\
\hline 8 & Evaluation and application & Assessment of achievement to goals, application of skills learned in the natural environment. \\
\hline
\end{tabular}


Table 2. Mean and standard deviation of variables

\begin{tabular}{|c|c|c|c|}
\hline \multirow{2}{*}{ Variables } & \multirow{2}{*}{ Situation } & \multicolumn{2}{|c|}{ Mean士SD } \\
\hline & & Intervention & Control \\
\hline \multirow{2}{*}{ Self-awarenes } & Pre-test & $25.40 \pm 4.27$ & $23.80 \pm 4.10$ \\
\hline & Post-test & $27.53 \pm 4.01$ & $23.80 \pm 4.11$ \\
\hline \multirow{2}{*}{ Self-manageme } & Pre-test & $35.13 \pm 6.47$ & $34.86 \pm 35.20$ \\
\hline & Post-test & $41.80 \pm 6.06$ & $3.85 \pm 3.87$ \\
\hline \multirow{2}{*}{ Social awarene } & Pre-test & $19.66 \pm 3.28$ & $18.20 \pm 2.33$ \\
\hline & Post-test & $21.93 \pm 3.73$ & $18.53 \pm 2.47$ \\
\hline \multirow{2}{*}{ Relationship mana } & Pre-test & $32.26 \pm 34.53$ & $30.93 \pm 4.07$ \\
\hline & Post-test & $4.68 \pm 5.09$ & $32.26 \pm 3.23$ \\
\hline \multirow{3}{*}{ Emotional intelligence } & Pre-test & $112.46 \pm 10.14$ & $107.80 \pm 5.40$ \\
\hline & & & \\
\hline & Post-test & $125.80 \pm 16.60$ & $109.60 \pm 4.89$ \\
\hline
\end{tabular}

informed consent form to allow the participation of their children in this study. Students were equally divided between the intervention and control groups. The researcher explained how to complete the emotional intelligence test using the total communication method and all participants completed this test in small groups under the supervision of the researcher.

The intervention group received a cognitive emotion regulation program in 8 sessions (twice a week and 45 minutes per session), while the control group did not participate in this program and was kept in the waiting list. The cognitive emotion regulation program was designed based on Gross and Thompson's emotion regulation strategies (Table 1) [31]. This intervention program has been applied in several studies [17].

The total communication method was used to interaction and training of students with hearing impairment. Powerpoint and film displaying pictures, and introducing emotions were used in the training sessions. Also, some skills such as position correction, expanding attention, cognitive assessment, and response adjustment were taught to the participants through conversation and verbal modeling. The use of these tools was one of the prominent features of this intervention program, which distinguishes it from other cognitive emotion regulation programs. At the end of the intervention, all subjects completed the emotional intelligence test again. Also, a 2-day workshop was conducted for the control group.
The obtained data were analyzed by multivariate analysis of covariance (MANCOVA) and analysis of covariance (ANCOVA) in SPSS.

\section{Results}

Demographic characteristics indicated the subject's age in the range of 16 to 20 years (mean=17.93 and standard deviation $=1.31$ years). To determine age differences between the intervention and control groups, we performed the $t$ test. The result showed no significant difference in the mean age between these groups $(\mathrm{t}=1.72, \mathrm{P}=0.25)$. Table 2 presents mean and standard deviation scores of emotional intelligence and subscales (self-management, self-awareness, relationship management, and social awareness) in the pre-test and post-test.

To compare the mean scores of self-awareness, selfmanagement, social awareness, and relationship management in groups, we performed MANCOVA. But first, we checked and verified the normality of study variables, also the assumption of variance equality was verified by using Levene's test $(\mathrm{P}>0.05)$. In addition, Box's $\mathrm{M}$ test approved the equality of variance-covariance matrices (Box's $\mathrm{M}=32.81, \mathrm{P}=0.002$ ). Therefore, MANCOVA could be applied. The total score of Wilk's lambda was significant indicating that the intervention and control groups had a significant difference, at least in one of the variables $\left(\mathrm{F}_{4,21}=5.06, \mathrm{P}=0.005\right)$. MANCOVA test was used to examine the differences among scores of 
Table 3. The results of the multivariate analysis of variance

\begin{tabular}{ccccccc}
\hline Variables & SS & df & MS & F & P & $\boldsymbol{\eta}^{2}$ \\
\hline Self-awareness & 29.08 & 1 & 29.08 & 12.96 & $<0.0001$ & 0.41 \\
\hline Self-management & 78.61 & 1 & 78.61 & 27.36 & $<0.0001$ & 0.61 \\
Social awareness & 48.38 & 1 & 48.38 & 15.06 & $<0.0001$ & 0.47 \\
Relationship management & 23.36 & 1 & 23.36 & 11.01 & $<0.0001$ & 0.44 \\
\hline
\end{tabular}

Table 4. The results of ANCOVA

\begin{tabular}{ccccccc}
\hline Source of Change & SS & df & MS & F & P & $\boldsymbol{\eta}^{2}$ \\
\hline Pre-test & 808.79 & 1 & 808.79 & 12.44 & $<0.002$ & 0.31 \\
Group & 2443.80 & 1 & 2443.80 & 37.61 & $<0.0001$ & 0.52 \\
\hline Error & 1754.19 & 27 & 64.97 & & & Пranian Rehabilitation Dournal \\
Total & 6166.30 & 29 & & &
\end{tabular}

self-management, self-awareness, relationship management, and social awareness between the intervention and control groups (Table 3).

As can be seen in Table 3, the intervention affected post-test scores, and there are significant differences between the intervention and control groups regarding the scores of self-management, self-awareness, relationship management, and social awareness $(\mathrm{P}<0.0001)$. Also, the results indicated that cognitive emotion regulation had a significant effect on self-awareness, self-management, social awareness, and relationship management $(\mathrm{P}<0.0001)$. According to the eta square results, it could be stated that $41 \%, 61 \%, 47 \%$, and $44 \%$ of the variation in each variable, respectively are due to the effect of cognitive emotion regulation program in the intervention group at the post-test.

To compare the emotional intelligence of groups in the post-test, ANCOVA was used. The normality of this variable and the equality of variances were tested. The Kolmogorov-Smirnov test confirmed the normality of this variable $(\mathrm{P}>0.05)$. The Levene's test indicated the equality of variances $(\mathrm{P}=0.33)$. The results of ANCOVA for comparing the emotional intelligence of intervention and control groups were reported in Table 4.

As shown in Table 4, there is a significant difference between the intervention and control groups in emotional intelligence $(\mathrm{P}<0.0001)$. Also, according to eta square results, $52 \%$ of the variation of emotional intelligence can be explained by participating in a cognitive emotion regulation program.

\section{Discussion}

The present research was conducted to determine the effect of cognitive emotion regulation on emotional intelligence in students with hearing impairment. Also, this study examined the effectiveness of cognitive emotion regulation training on self-management, self-awareness, relationship management, and social awareness of students with hearing impairment in the intervention and control groups.

The present study supports the effectiveness of emotion regulation on emotional intelligence and subscales (selfmanagement, self-awareness, relationship management, and social awareness) in students with hearing impairment. The result of the present study was consistent with the study results of Shahba, Alvani, Zahedi, and Memarzadeh, who reported that the cognitive emotion regulation strategies improved job satisfaction of subjects [23].

The finding of this research was similar to the research results of Kobylinska and Kusev, who reported the cognitive emotion regulation improved the emotional intelligence of subjects [25]. The current research finding was similar to the research finding of Gross, who stated that the emotion regulation program improved cognitive and 
social consequences in the participants [26]. The finding of the current study was similar to the research finding of Bucich and MacCann, who showed that emotional intelligence improved social sharing in people with hearing impairment [27]. The finding of the present research was consistent with the study results of Tajrishi, Ashori, and Jalil-Abkenar, who reported that the emotional intelligence program improved the mental health of deaf students [7]. Also, research results of Ashori, Jalil-Abkenar, and Pourmohammadreza-Tajrishi revealed that the emotional intelligence program improved self-esteem in students with hearing impairment [30].

To explain these findings, it can be stated that over the recent decades, the interest in cognitive emotion regulation programs has been growing [14] because these programs offer a systematic approach and procedure to improve emotion regulation in people [21]. The cognitive emotion regulation included awareness of emotions, emotional perception skills, and position choice, prevention skills, position correction, expanding attention, cognitive assessment, response adjustment, evaluation, and application [17]. On the other hand, students with hearing impairment have problems with emotional intelligence. The development of emotional intelligence along with significant problems for students with hearing impairment, especially students with severe and profound hearing impairment. It seems that these students have problems with their self-management, self-awareness, relationship management, and social awareness [30]. When students with hearing impairment participate in the cognitive emotion regulation training, this program can improve brain function and emotional intelligence [21]. Then, it is expected that the cognitive emotion regulation program improves emotional intelligence as well as self-management, self-awareness, relationship management, and social awareness in students with hearing impairment.

Besides, sometimes hearing loss leads to rejection, depression, and low social activity [33]. Hearing impairment is an inappropriate condition in hearing that affects emotional intelligence [7] and included self-management, self-awareness, relationship management, and social awareness [34]. Emotions are regulated through intrapersonal and interpersonal processes [35]. Emotion regulation comprises the internal and external processes to evaluating, monitoring, and changing emotional reactions, especially of strong and temporary nature to achieve goals [15]. More precisely, intrinsic interpersonal emotion is a process by which a person regulates own emotions with the help of another person, while extrinsic interpersonal emotion is a process by which a person regulates others' emotions [36]. Because of that, the cognitive emotion regulation program improved intrapersonal and interpersonal processes [21]. Moreover, cognitive emotion regulation improves appropriate behaviors and skills, increases the neuroplasticity of the nervous system in the children, and increases emotional intelligence. Because the cognitive emotion regulation program is multi-dimensional and focuses on cognitive and emotional skills, it is expected that it will improve the emotional intelligence of students with hearing impairment.

It is important to mention several limitations of the present research. First, only prelingually deaf students aged 16-20 years old participated in this research. Second, the study disregarded the method of communication with these students, hearing status in each ear of students, personality traits, and their socio-economic status. Third, the opportunity to follow up on results was not provided. The present result offers some suggestions for further research. First, it is suggested that prelingually and postlingually deaf students of different ages be studied. Second, regarding the method of communication with these students, hearing status in each ear of the students, their personality traits, and socio-economic status should be investigated. Third, it is recommended that a follow-up stage be provided.

\section{Conclusion}

Since emotional intelligence is a multidimensional and complex phenomenon, students with hearing impairment require a special educational program, such as emotion regulation. That is expected that an emotion regulation training program improves emotional intelligence in students with hearing impairment. Also, cognitive emotion regulation facilitates the development of emotional intelligence in students with hearing impairment. Thus, paying attention to emotion regulation training plays an important role in enhancing emotional intelligence in these students. Ultimately, this research showed significant improvement in the emotional intelligence of students with hearing impairment, who participated in the cognitive emotion regulation program.

\section{Ethical Considerations}

\section{Compliance with ethical guidelines}

The present research was confirmed by the Human Ethics Research Committee of the University of Isfahan and Exceptional Education Organization in Isfahan, Iran. 


\section{Funding}

This research did not receive any specific grant from funding agencies in the public, commercial, or not-forprofit sectors.

\section{Authors' contributions}

Conceptualization and investigation, writing the original draft: Mohammad Ashori and Azam Rashidi; Methodology, supervision, writing, review, and editing the manuscript: Mohammad Ashori; Resources: Azam Rashidi.

\section{Conflict of interest}

The authors declared no conflict of interest.

\section{Acknowledgments}

The author like to acknowledge the support of the Exceptional Education Organization in Isfahan and Mir Deaf School for their sincere cooperation whose support made it possible conducting this research.

\section{References}

[1] Kirk S, Gallagher JJ, Coleman MR. Educating exceptional children. 14 $4^{\text {th }}$ ed. Boston: Cengage Learning; 2015. https:// books.google.com/books?id=kVo8AwAAQBAJ\&printsec $=$ frontcover\&source $=$ gbs_ge_summary_r\&cad $=0 \# v=$ onep age\& $q \mathrm{f}=$ false

[2] Lawyer G. Deaf education and deaf culture: Lessons from Latin America. American Annals of The Deaf. 2018 162(5):486-8. [DOI:10.1353/aad.2018.0006]

[3] Korver AMH, Smith RJH, Van Camp G, Schleiss MR, Bitner-Glindzicz MAK, Lustig LR, et al. Congenital hearing loss. Nature Reviews Disease Primers. 2017; 3:16094. [DOI:10.1038/nrdp.2016.94] [PMID] [PMCID]

[4] Hallahan DP, Kauffman JM, Pullen PC. Exceptional learners: An introduction to special education. $14^{\text {th }}$ ed. London: Pearson; 2018. https://www.google.com/books/edition/ Exceptional_Learners/RqzIPgAACAAJ?hl=en

[5] Ashori M, Jalil Abkenr SS. Students with special needs and inclusive education. Tehran: Roshd-e Farhang; 2019.

[6] Jalil-Abkenar SS, Ashori M, Pourmohamadreza-Tajrishi M, Hasanzadeh S. Auditory perception and verbal intelligibility in children with cochlear implant, hearing aids and normal hearing. Practice in Clinical Psychology. 2013; 1(3):141-7. http:/ /jpcp.uswr.ac.ir/article-1-89-en.html

[7] Pourmohamadreza-Tajrishi M, Ashori M, Jalil-Abkenar SS. The effectiveness of emotional intelligence training on the mental health of male deaf students. Iranian Journal of Public Health. 2013; 42(10):1174-80. https://ijph.tums ac.ir/index.php/ijph/article/view/4379

[8] Mattingly V, Kraiger K. Can emotional intelligence be trained? A meta-analytical investigation. Human Resource Management Review. 2019; 29(2):140-55. [DOI:10.1016/j. hrmr.2018.03.002]

[9] Dolev N, Goldental N, Reuven-Lelong A, Tadmor T. The evaluation of emotional intelligence among medical students and its links with non-cognitive acceptance measures to medical school. Rambam Maimonides Medical Journal. 2019; 10(2):e0010. [DOI:10.5041/RMMJ.10365] [PMID] [PMCID]

[10] Gribble N, Ladyshewsky RK, Parsons R. Fluctuations in the emotional intelligence of therapy students during clinical placements: Implication for educators, supervisors, and students. Journal of Interprofessional Care. 2017; 31(1):8-17. [DO I:10.1080/13561820.2016.1244175] [PMID]

[11] Abe K, Niwa M, Fujisaki K, Suzuki Y. Associations between emotional intelligence, empathy and personality in Japanese medical students. BMC Medical Education. 2018; 18(1):47. [DOI:10.1186/s12909-018-1165-7] [PMID] [PMCID]

[12] Almeida GFL, Martins MF, da Costa LBA, da Costa OA, Martinho de Carvalho AC. Sequential bilateral cochlear implant: Results in children and adolescents. Brazilian Journal of Otorhinolaryngology. 2019; 85(6):774-9. [DOI:10.1016/j. bjorl.2018.07.008] [PMID]

[13] Gregoire S, Lachance L, Taylor G. Mindfulness, mental health and emotion regulation among workers. International Journal of Wellbeing. 2015; 5(4):96-119. [DOI:10.5502/ijw.v5i4.444]

[14] Domaradzka E, Fajkowska M. Cognitive emotion regulation strategies in anxiety and depression understood as types of personality. Frontiers in Psychology. 2018; 9:856. [DOI:10.3389/fpsyg.2018.00856] [PMID] [PMCID]

[15] Zaki J, Williams WC. Interpersonal emotion regulation Emotion. 2013; 13(5):803-10. [DOI:10.1037/a0033839] [PMID]

[16] Garnefski N, Kraaij V. Relationships between cognitive emotion regulation strategies and depressive symptoms: A comparative study of five specific samples. Personality and Individual Differences 2006; 40(8):1659-69. [DOI:10.1016/j. paid.2005.12.009]

[17] Gross JJ. Emotion regulation: Current status and future prospects. Psychological Inquiry. 2015; 26(1):1-26. [DOI:10.10 80/1047840X.2014.940781]

[18] Gross JJ, Jazaieri H. Emotion, emotion regulation and psychopathology: An affective science perspective. Clinical Psychological Science: A Journal of The Association for Psychological Science. 2014; 2(4):387-401. [DOI:10.1177/2167702614536164]

[19] Pejičić M, Ristić M, Anđelković V. The mediating effect of cognitive emotion regulation strategies in the relationship between perceived social support and resilience in postwar youth. Journal of Community Psychology. 2018; 46(4): 457-72. [DOI:10.1002/jcop.21951]

[20] Kraaij V, Garnefski N. The behavioral emotion regulation questionnaire: Development, psychometric properties and relationships with emotional problems and the cognitive emotion regulation questionnaire. Personality and Individual Differences. 2019; 137:56-61. [DOI:10.1016/j.paid.2018.07.036] 
[21] Wang J, Zhou N, Wang D, Yu P, Xiao J. The effect of cognitive emotion regulation strategies on gynecologic oncology: Comparison between a clinical and a non-clinical sample. Journal of Psychosomatic Obstetrics \& Gynecology. 2018; 39(4):259-65. [DO I:10.1080/0167482X.2017.1345883] [PMID]

[22] Ashori M, Yazdanipour M, Pahlavani M. The effectiveness of cognitive rehabilitation program on auditory perception and verbal intelligibility of deaf children. American Journal of Otolaryngology-Head and Neck Medicine and Surgery. 2019; 40(5):7248. [DOI:10.1016/j.amjoto.2019.06.011] [PMID]

[23] Shahba S, Alvani SM, Zahedi SA, Memarzadeh G. An investigation on the effect of cognitive emotion regulation strategies on job satisfaction. Management Science Letters. 2014; 4(6):1315-24. [DOI:10.5267/j.msl.2014.4.010]

[24] Peña-Sarrionandia A, Mikolajczak M, Gross JJ. Integrating emotion regulation and emotional intelligence traditions: A meta-analysis. Frontiers in Psychology. 2015; 6:160. [DOI:10.3389/ fpsyg.2015.00160] [PMID] [PMCID]

[25] Kobylinska D, Kusev P. Flexible emotion regulation: How situational demands and individual differences influence the effectiveness of regulatory strategies. Frontiers in Psychology. 2019; 10:72. [DOI:10.3389/fpsyg.2019.00072] [PMID] [PMCID]

[26] Gross JJ. Emotion regulation: Affective, cognitive, and social consequences. Psychophysiology. 2002; 39(3):281-91 . [DOI:10.1017/S0048577201393198] [PMID]

[27] Bucich M, MacCann C. Emotional intelligence and day-today emotion regulation processes: Examining motives for social sharing. Personality and Individual Differences. 2019; 137:22-6. [DOI:10.1016/j.paid.2018.08.002]

[28] Schoorl J, van RijnS, de Wied M, Van GoozenS, Swaab H. Emotion regulation difficulties in boys with oppositional defiant disorder/conduct disorder and the relation with comorbid autism traits and attention deficit traits. PloS One. 2016; 11(7):e0159323. [DOI:10.1371/journal.pone.0159323] [PMID] [PMCID]

[29] Domaradzka E, Fajkowska M. Cognitive emotion regulation strategies in anxiety and depression understood as types of personality. Frontiers in Psychology. 2018; 9:856. [DOI:10.3389/fpsyg.2018.00856] [PMID] [PMCID]

[30] Ashori M, Jalil-Abkenar SS, Pourmohammadreza-Tajrishi M [Investigation of the effectiveness of emotional intelligence training on the self-esteem and mental health in boy deaf students (Persian)]. Archives of Rehabilitation. 2014; 15(1):3-12. http:// rehabilitationj.uswr.ac.ir/article-1-1311-en.html

[31] Bradberry T, Greaves J. The emotional intelligence quick book: Everything you need to know. San Diego: Talent Smart; 2003.

[32] Ganji H, Mirhashemi M, Sabet M. [Bradberry-Greaves' emotional intelligence test: Preliminary norming-process (Persian)] Journal of Thought and Behavior. 2005; 1(2):23-35. http:/ / ensani. ir/file/download/article/20101111140056-

[33] Shin HY, Hwang HJ. Mental health of the people with hearing impairment in Korea: A population-based cross-sectional study. Korean Journal of Family Medicine. 2017; 38(2):57-63. [DOI:10.4082/kjfm.2017.38.2.57] [PMID] [PMCID]

[34] Owji M, Sahraian MA, Bidadian M, Ghadiri F, Etesam F, Azi$\mathrm{mi} \mathrm{A}$, et al. Evaluating the relationship between emotional intelligence and cognitive disorders in patients with Multiple Sclerosis. Iranian Journal of Neurology. 2018; 17(2):78-81. [PMID] [PMICD]
[35] Hofmann SG. Interpersonal emotion regulation model of mood and anxiety disorders. Cognitive Therapy and Research. 2014; 38(5):483-92. [DOI:10.1007/s10608-014-9620-1] [PMID] [PMCID]

[36] Hofmann SG, Carpenter JK, Curtiss J. Interpersonal Emotion Regulation Questionnaire (IERQ): Scale development and psychometric characteristics. Cognitive Therapy and Research. 2016; 40(3):341-56. [DOI:10.1007/s10608-016-9756-2] [PMID] [PMCID] 
This Page Intentionally Left Blank 